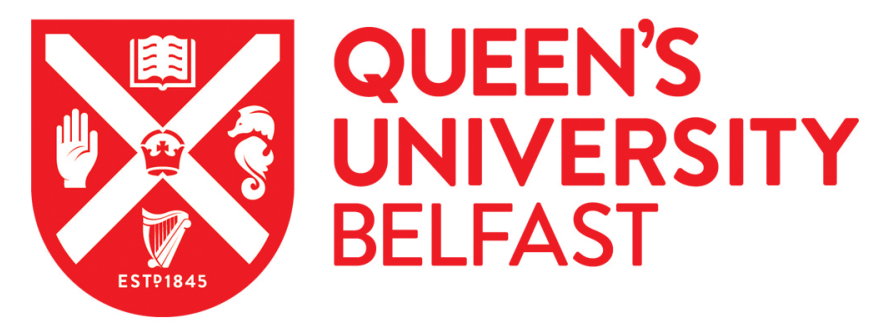

\title{
Identification of novel Amurin-2 variants from the skin secretion of Rana amurensis, and the design of cationicity-enhanced analogues
}

Zhang, L., Chen, X., Zhang, Y., Ma, C., Xi, X., Wang, L., Zhou, M., Burrows, J., \& Chen, T. (2018). Identification of novel Amurin-2 variants from the skin secretion of Rana amurensis, and the design of cationicity-enhanced analogues. Biochemical and Biophysical Research Communications, 1-11.

https://doi.org/10.1016/j.bbrc.2018.01.124

Published in:

Biochemical and Biophysical Research Communications

Document Version:

Peer reviewed version

Queen's University Belfast - Research Portal:

Link to publication record in Queen's University Belfast Research Portal

Publisher rights

(c) 2018 Published by Elsevier Inc. This work is made available online in accordance with the publisher's policies. Please refer to any applicable terms of use of the publisher.

\section{General rights}

Copyright for the publications made accessible via the Queen's University Belfast Research Portal is retained by the author(s) and / or other copyright owners and it is a condition of accessing these publications that users recognise and abide by the legal requirements associated with these rights.

Take down policy

The Research Portal is Queen's institutional repository that provides access to Queen's research output. Every effort has been made to ensure that content in the Research Portal does not infringe any person's rights, or applicable UK laws. If you discover content in the Research Portal that you believe breaches copyright or violates any law, please contact openaccess@qub.ac.uk. 
1 Identification of novel Amurin-2 variants from the skin secretion of Rana

2 amurensis, and the design of cationicity-enhanced analogues

\author{
3 Luyao Zhang ${ }^{1, \dagger}$, Xiaoling Chen ${ }^{1, \dagger}$, Ying Zhang ${ }^{1,2}$, Chengbang Ma ${ }^{1, *}$, Xinping $\mathrm{Xi}^{1{ }^{1, *}}$, Lei Wang ${ }^{1}$, Mei \\ Zhou ${ }^{1}$, James F. Burrows ${ }^{1}$ and Tianbao Chen ${ }^{1}$ \\ 1 School of Pharmacy, Queen's University, Belfast BT9 7BL, Northern Ireland, UK. \\ 2 Clinical trial center, Beijing Hospital, Beijing, 100730, China. \\ $\dagger$ These authors contributed equally to this work. \\ * Correspondence: c.ma@qub.com (C.M.); x.xi@qub.ac.uk (X.X.); Tel.: +44-028-9097-1673.
}

\title{
Highlights
}

Three novel Amurin-2 variants were identified from the skin secretion of Rana amurensis.

- Cationic-enhanced analogues show broader antimicrobial activity spectrums.

- The substitution by Lys at position 4 improves the antimicrobial selectivity on E. coli.

- The cell lysis ability of Amurin-2 peptides is associated with their positive charge.

\begin{abstract}
Rana amurensis is important in Chinese medicine as its skin secretions contain abundant bioactive peptides. Here, we have identified the antimicrobial peptide Amurin-2 and three highly-conserved variants, Amurin-2a, Amurin- $2 b$ and Amurin-2c through a combination of molecular cloning and MS/MS fragmentation sequencing. Synthetic replicates of these peptides demonstrate potent antimicrobial activity against S. aureus, whilst some have activity against C.albicans and even resistant bacterial MRSA. Furthermore, two Lysanalogues $\left(\mathrm{K}^{4}\right.$-Amurin-2 and $\mathrm{K}^{11}$-Amurin-2) were designed to improve the bioactive function and the antimicrobial activity of $\mathrm{K}^{4}$-Amurin-2 against E.coli was enhanced distinctly. In addition, the two modified peptides also showed more potent activity against S. aureus, C. albicans and MRSA strains. Meanwhile, these peptides showed inhibitory effect on the cell viability of several cancer cells. As a result, these structural and functional studies of Amurin-2 variants and analogues could provide insights for future antimicrobial peptide design.
\end{abstract}

Keywords: antimicrobial peptide; amphibian skin secretion; cationicity-related peptide design.

\section{Introduction}

Antimicrobial peptides (AMPs) are abundant in amphibian skin secretions, with more than 300 disparate kinds of AMPs having been discovered already from frog species [1]. In particular, numerous AMP families with various functions have been discovered from frogs of the Ranidae family in recent years. The peptides in the skin secretions of frogs mainly help them to defend against microorganisms they come into contact with and it is common for close species to have AMP families with highly conserved coding sequences within their signal peptides, but diverse sequences within the pro-peptides. A series of peptide variants of the same AMP family can be isolated from one frog species. The hyper-mutations of frog-derived peptides can be induced by environmental or bacterial challenges [5] and these variants can be retained owing to their survival value in natural selection. Examples of this include six peptides (Brevinin-1Ba f) from the Brevinin subfamily isolated from the skin of Lithobates berlandieri [2] and ten Temporins isolated from the skin of Rana temporaria [3]. These AMP variants produced by the same species can act together to enhance their combined antimicrobial activity, something demonstrated via the studies of Temporin A, B with $\mathrm{L}$ on gram positive strains [4, 5]. Additionally, variants of

\footnotetext{
${ }^{1}$ Abbreviations: AMP, antimicrobial peptide; MRSA, methicillin-resistant Staphylococcus aureus; HDPs, hostdefence peptides; CD, circular dichroism; MHB, Mueller-Hinton Broth; MIC, minimum inhibitory concentration; FBS, foetal bovine serum; MTT, 3-(4,5-Dimethylthiazol-2-Yl)-2,5-Diphenyltetrazolium Bromide; UTR, untranslated region; $\mathrm{HC}_{50}$, half haemolytic concentrations; $\mathrm{IC}_{50}$, half maximal inhibitory concentration;
} 
one AMP can be distributed in closely related frog species [6], such as the Brevinins which have been isolated from the Rana genus and Dermaseptins from the Phyllomedusa genus [7, 8].

In this report, we have identified four wild-type peptides (Amurin-2, Amurin-2a, Amurin-2b and Amurin2c) of the Amurin family from the skin secretions of the Heilongjiang brown frog, Rana amurensis. Through a multi-sequence alignment we have shown that the nucleotide sequences of the four precursor peptides show a high degree of similarity. The mature Amurin-2c has the same amino acid sequence as Brevinin-2CDYc which was isolated from Rana dybowskii. In addition, two peptide analogues were synthesized to study the functional rules of Amurin-2 variants on microorganisms. Even though the mature peptides are highly similar, we have found these six peptides show different antimicrobial and anti-proliferative potencies.

\section{Materials and Methods}

\section{Rana amurensis Skin Secretion Harvesting}

The Rana amurensis frog specimens, which were all adults, were derived from the Jilin province of the Peoples Republic of China. The skin secretions of four Rana amurensis frog specimens were obtained as described previously [9].

\section{'Shot gun' Cloning of Amurin-2 variants precursor-encoding cDNAs}

The molecular cloning was carried out as described previously [9]. The isolated mRNA was subjected to the 3'-RACE procedures using a degenerate primer (S1; 5'-GAWYYAYYHRAGCCYAAADATG-3', W=A+T; $\mathrm{Y}=\mathrm{T}+\mathrm{C} ; \mathrm{H}=\mathrm{A}+\mathrm{C}+\mathrm{T} ; \mathrm{R}=\mathrm{A}+\mathrm{G} ; \mathrm{D}=\mathrm{A}+\mathrm{G}+\mathrm{T}$ ) that was designed to a highly-conserved domain of the 50-untranslated region of previously characterized peptide precursor cDNAs from closely-related Rana species.

\section{Identification and structural analysis of Amurin-2 variants}

The supernatant of centrifuged skin secretion was decanted and pumped directly onto an analytical reverse phase HPLC column (Phenomenex C-18, $25 \mathrm{~cm} \times 0.45 \mathrm{~cm}$ ) that was attached to a Cecil CE4200 Adept gradient reverse phase HPLC system (Cecil Instruments Limited, Cambridge, UK). Peptides were eluted using a gradient formed from 0.05/99.5 (v/v) TFA/water to 0.05/19.95/80.0 (v/v/v) TFA/water/acetonitrile in $240 \mathrm{~min}$ at a flow rate of $1 \mathrm{ml} / \mathrm{min}$ directly into a Thermo Fisher Scientific LCQ Fleet electrospray ion-trap mass spectrometer in positive detection mode. By means of data-dependent acquisition, doubly charged peptide ions detected in the mass spectrometer were automatically subjected to MS/MS fragmentation.

\section{Syntheses of Amurin-2 variants and the Lys-analogues}

Amurin-2, Amurin-2a, Amurin-2b, Amurin-2c, $\mathrm{K}^{4}$-Amurin-2 and $\mathrm{K}^{11}$-Amurin-2 were synthesized by solidphase Fmoc chemistry using a Tribute ${ }^{\circledR}$ Peptide Synthesizer (Protein Technologies, Tucson, AZ, USA).The Fmoc protection groups were removed by $20 / 80(\mathrm{v} / \mathrm{v})$ Piperidine/dimethylformamide and the peptide bond was coupled in the presence of 2-(1H-benzotriazol-1-yl)-1,1,3,3-tetramethyluronium hexafluorophosphate (HBTU), dissolving in 11/89 (v/v) N-methylmorpholine/dimethylformamide. Following cleavage from the resin and deprotection by a reaction containing 2/2/2/94 (v/v/v/v) 1,2-ethanedithiol/ $\mathrm{H}_{2} \mathrm{O} /$ thioanisole/TFA for $2 \mathrm{~h}$ at room temperature. The peptide was washed using diethyl ether and dissolved in 0.05/99.95 (v/v) TFA/water. A final concentration of $0.01 \%$ of $\mathrm{H}_{2} \mathrm{O}_{2}$ was added to perform the formation of the disulphide bond.

\section{Secondary structural analyses of Amurin-2 variants and the Lys-analogues through circular dichroism (CD) spectroscopy}

The sample peptide solutions $(50 \mu \mathrm{M})$ were prepared in $10 \mathrm{mM}$ ammonium acetate initially in a $1 \mathrm{~mm}$ high precision quartz cell (Hellma Analytics, Essex, UK). CD measurements were performed at room temperature by a JASCO J-815 CD spectrometer (Jasco, Essex, UK) across the wavelength range from $190 \mathrm{~nm}-250 \mathrm{~nm}$. The scanning speed was $100 \mathrm{~nm} / \mathrm{min}$, the bandwidth was $1 \mathrm{~nm}$ and the data pitch was $0.5 \mathrm{~nm}$.

\section{Antimicrobial susceptibility tests of Amurin-2 variants and the Lys-analogues}


The antimicrobial susceptibility tests of Amurin-2 variants were performed on Staphylococcus aureus (G+ bacteria, NCTC 10788), Escherichia coli (G- bacteria, NCTC 10418), Candida albicans (yeast, NCPF 1467) and MRSA (Methicillin-resistant Staphylococcus aureus, ATCC 12493). These microorganisms were grown in Mueller-Hinton Broth (Oxoid, Basingstoke, Hampshire, UK) (MHB) at $37^{\circ} \mathrm{C}$. The MIC values were tested as in our previous study [9].

\section{Cell viability test of Amurin-2 variants and the Lys-analogues on cell lines}

The cancer cell lines H157 (ATCC-CRL-5802, ATCC, Teddington, Middlesex, UK) and PC-3 (ATCC-CRL1435 ) were cultured in RPMI-1640 culture medium (Invitrogen, Paisley, UK) containing 10\% FBS and 1\% Penicillin-Streptomycin. The cancer cell lines U251MG (ECACC-09063001, ECACC, Salisbury, UK), MDAMB-435s (ATCC-HTB-129) and MCF-7 (ATCC-HTB-22) were cultured in RPMI-1640 culture medium (Invitrogen, Paisley, UK) containing 10\% FBS and 1\% Penicillin-Streptomycin. The normal cell line HMEC-1 (ATCC-CRL-3243) was cultured in MCDB131 medium (Gibco, Paisley, UK) containing 10\% FBS, $10 \mathrm{ng} / \mathrm{ml}$ epidermal growth factor (EGF), $1 \mu \mathrm{g} / \mathrm{mL}$ hydrocortisone, $10 \mathrm{mM}$ Glutamine and $1 \%$ penicillin streptomycin to test the toxicity of peptides on normal cells. The cell viability test using MTT was performed as described previously [9].

\section{Haemolytic activity test of Amurin-2 variants and the Lys-analogues}

The haemolytic activity test was performed using completely washed horse erythrocytes (TCS Biosciences Ltd., Buckingham, UK) and carried out as previously described [9]. 1\% of Triton X-100 (Sigma-Aldrich, St. Louis, MO, USA) was used as the positive control. The absorbance measured by a Synergy HT plate reader (BioTek Instruments, Inc., Winooski, VT, USA) at $550 \mathrm{~nm}$.

\section{Results}

\section{Precursor-encoding cDNA of Amurin-2 variants from the skin secretions of Rana amurensis}

From the skin secretion cDNA library, four highly-conserved sequences were obtained using the same degenerate primer (Figure S1). One of four sequences isolated is identical to the previously identified cDNA of the Amurin-2 precursor [10]. The topological structures of the four precursors contain several domains including a signal peptide containing 22 amino acids, a 23-mer acidic spacer peptide, a typical -KR-convertase processing site and the mature peptide domain. Due to the high degree of similarity between these four cDNAs (Figure 1), we named the other three variants as Amurin-2a, Amurin-2b and Amurin-2c, respectively.

\section{Isolation of Amurin-2 and variants from the skin secretion of the Rana amurensis}

The skin secretion of Rana amurensis was successfully fractionated within 240 min under the linear gradient. The presence of Amurin-2 and variants were confirmed and the primary structures are consistent with the cDNA encoding mature peptide (Table 1). Amurin-2 and the variants were eluted at $40 \%-50 \% \mathrm{ACN}$ and indicated in the chromatography (Figure 2). The MS/MS analysis showed that Amurin-2a and Amurin-2b were co-eluted at about 126 min; Amurin-2 and Amurin-2c were eluted at about $122 \mathrm{~min}$ and 119 min respectively.

\section{Physio-chemical properties of synthetic natural peptides and two Lys-substituted analogues}

Four natural peptides were synthesized and purified and the charge and hydrophobicity were calculated (Table 1). The helical wheel projects showed that Amurin-2 and Amurin-2c have one more positive charge on the hydrophilic phase than Amurin-2a and Amurin-2b. Two Lysine-substituted analogues ( $\mathrm{K}^{4}$-Amurin-2 and $\mathrm{K}^{11}$ Amurin-2) were designed based on Amurin-2a due to its slight haemolytic activity. The positive charge on the hydrophilic phase of the two analogues were enhanced while $\mathrm{K}^{4}$-Amurin-2 showed a large hydrophilic surface (Figure 3A). The CD spectra (Figure 3B) indicated that all peptides formed typical $\alpha$-helix structure in the membrane-mimic environment. The calculated helicities of all peptides are also shown in table 1 . 
To examine the antimicrobial properties of the different peptides we identified their minimum inhibitory more potent effects against wild-type $S$. aureus when compared to the other microorganisms and MRSA (Table 2). Amurin-2a and Amurin-2b only inhibited the growth of $S$. aureus, as well as exhibiting lower haemolysis. The two modified peptides (K4-Amurin-2, K11-Amurin-2) demonstrated markedly enhanced activity against all the microorganisms, but also showed enhanced haemolytic activity. $\mathrm{K}^{4}$-Amurin-2 even had significant activity against E. coli. A summary of the MICs and half haemolytic concentrations of all the peptides are shown in Table 2 .

\section{Cell viability test of Amurin-2 variants and analogues}

To determine if these peptides also had anti-proliferative activity against human cancer cells we next examined their impact upon a range of cancer and normal cells. All peptides exhibited broad-spectrum activity against the cell viability of tested cancer cell lines as well as the normal cell line, HMEC-1 (Figure 4), and the corresponding $\mathrm{IC}_{50}$ are listed in Table 3. Amurin-2 and Amuin-2c show more potent effect than the others. By contrast, Amurin-2a and Amurin-2b have less potent effects on the viability of H157 and MB435 cells at the highest concentrations.

\section{Discussion}

In a previous study we identified Amurin-2 from the dried skin extraction of Rana amurensis [10]. Here, a further three Amurin-2 variants were isolated from the skin secretion of the same frog species. The observation of multiple AMP variants has previously been reported in species from Ranidae family $[2,3]$ and although there is no clear explanation for the co-expression of such peptide variants, it was speculated that these different variants are present as they provide broader spectrum antimicrobial activity and so form part of a unique survival strategy to protect these species of frog [11]. The Amurin-2 variants are highly similar to Brevinin-1CDYb from the skin secretions of the Dybowski's frog [12,13]. Rana amurensis $(2 \mathrm{n}=26)$ and Rana dybowskii $(2 \mathrm{n}=24)$ are not closely related and their genomes consist of different numbers of chromosomes, further indicating their relatively distant taxonomic relationship $(\mathrm{D}=1.177)$. However, the conservation of the cDNA sequences of Amurin-2 and Brevinin$1 \mathrm{CDYb}$ (Identity=86.5\%) [14] indicates these AMPs have been maintained due to their importance in the antimicrobial defence of these different species.

Although the Amurin-2 variants isolated here are structurally conserved, their biological activities were markedly different. In particular, Amurin-2 and Amurin-2c showed potent activity against C.albicans and MRSA but Amurin-2a and Amurin-2b showed little activity against these strains. It has been speculated that positive charges at the hydrophilic phase can remarkably enhance the initial electrostatic interaction between peptides and negatively-charged cell membranes [6]. Therefore the observation that the haemolytic activates of Amurin-2a and Amurin- $2 \mathrm{~b}$ are less potent than the others was consistent with the lower charge which they exhibit. In addition, Amurin-2b is slightly more potent than Amurin-2a, indicating that its larger proportion of hydrophilic surface could enhance its activity, but the impact of this is lower than that produced by difference in cationicity. Indeed, some studies have indicated that AMPs with an uninterrupted hydrophobic residue region show less haemolysis, whilst maintaining antimicrobial activity [15].

When compared to Amurin-2a, the electro-positivity of the hydrophilic phases of the two modified peptides, $\mathrm{K}^{4}$-Amurin-2 and $\mathrm{K}^{11}$-Amurin-2, were increased and thus the antimicrobial and haemolytic activities were enhanced significantly. Indeed, $\mathrm{K}^{4}$-Amurin-2 even demonstrated potent activity against $E$. coli. In regards to their helical structure, we would assume that the composition of the hydrophilic surface of the Amurin peptides significantly influences their biological activity. The more cationic they are on their hydrophilic surface, the more potent the membrane interaction, which should increase their antimicrobial, haemolytic and cytotoxic activity. In addition, $\mathrm{K}^{4}$-Amurin-2 is the only peptide with activity against $E$. coli $(\mathrm{MIC}=16 \mu \mathrm{M})$, and the substitution of $\mathrm{Leu}^{4}$ with $\mathrm{Lys}^{4}$ at the hydrophilic phase increases the amphipathcity of the peptide. The stronger amphipathic activity of $\mathrm{K}^{4}$-Amurin-2 probably allows it to pass through the dense cell wall of E. coli directly. Indeed, the outermembrane of $E$. coli cells are mainly composed of amphipathic lipopolysaccharides, whilst the cell wall of $S$. aureus is constituted mainly of electro-negative peptidoglycans. In addition, a previous study of Magainin analogues indicates relatively high hydrophobic moment will directly increase membrane binding and the permeabilisation [16]. 
Conversely, the Amurin-2a and Amurin-2b have the similar hydrophobic surface as the other peptides, but one positive charge less. The observation of the lower haemolytic activities of Amurin-2a and Amurin-2b indicates the ability of cell lysis of these peptides is correlated with their cationicity, which have been considered as emphases in the sequence designing $[17,18]$. In addition, the proline residue, which is known to make a hinge as a helix breaker, the presence of proline at position 3 decreases the haemolytic activity of two modified analogues when comparing to Amurin-2 and Amurin-2c, indicating that the helical kink is related to the selectivity of Amurin peptides [19]. Although, the Lys substituted at position 4 increases the amphipathcity that improve the permeabilisation of $E$. coli cells, it remains the same haemolysis with $\mathrm{K}^{11}$-Amurin-2. The charge induced at position 4 enhances the selectivity on E. coli instead of non-specific permeability. The reason is not clear so for, but we assume that might be related to the $\mathrm{N}$-terminal hinge region which could help to expose the positive charge to the negatively-charged LPS and dig into the internal region of $E$. coli cell envelope.

Generally, $\alpha$-helical domain is also associated with the bioactivity of AMPs [16], but in this study, the CD results showed unclear correlation between peptide activity and $\alpha$-helical domain. It is speculated that the function is more related to the distribution of amino acids residue on the surface of $\alpha$-helical structure rather than the helix proportion itself. The anti-cancer activity of the six peptides is similar to their haemolytic functions and this may be due to their impact upon mammalian cell membranes which have similar lipid compositions [20]. However, $\mathrm{K}^{11}$-Amurin-2 showed a lower activity against MCF-7 cells. The reason for this is not clear but possibly the substitution of Ser ${ }^{11}$ with Lys ${ }^{11}$ may somehow influence the targeting of this peptide to MCF-7 cells.

In summary, three Amurin-2 variants were identified from the skin secretion of Rana amurensis and two Lys-analogues were designed to perform a structure-activity study. Basically, increasing the net positive charges of Amurin peptides could improve the antimicrobial activity as well as the haemolytic activity. But the prolinerelated kink conformation is helpful to reduce the haemolytic activity. The substitution by positively-charged Lys at positive 4 can enhance the selectivity on E. coli, however, the reason needs to be further investigated.

Author Contributions: T.C., M.Z. and L.W. conceived and designed the experiments; L.Z., X.C. and Y.Z. performed the experiments; L.Z., X.C and M.C. analysed the data; L.Z., M.C. and X.X. wrote the paper; J.B. and T.C. revised the paper.

Conflicts of Interest: The authors declare no conflict of interest.

\section{References}

[1] A.A. Bahar, D. Ren, Antimicrobial peptides, Pharmaceuticals, 6 (2013) 1543-1575.

[2] J. Goraya, Y. Wang, Z. Li, M. O'Flaherty, F.C. Knoop, J.E. Platz, J.M. Conlon, Peptides with antimicrobial activity from four different families isolated from the skins of the North American frogs Rana luteiventris, Rana berlandieri and Rana pipiens, The FEBS Journal, 267 (2000) 894-900.

[3] M. Simmaco, G. Mignogna, S. Canofeni, R. Miele, M.L. Mangoni, D. Barra, Temporins, antimicrobial peptides from the European red frog Rana temporaria, European Journal of Biochemistry, 242 (1996) 788-792.

[4] Y. Rosenfeld, D. Barra, M. Simmaco, Y. Shai, M.L. Mangoni, A synergism between Temporins toward Gram-negative bacteria overcomes resistance imposed by the lipopolysaccharide protective layer, Journal of Biological Chemistry, 281 (2006) 28565-28574.

[5] R. Capparelli, A. Romanelli, M. Iannaccone, N. Nocerino, R. Ripa, S. Pensato, C. Pedone, D. Iannelli, Synergistic antibacterial and anti-inflammatory activity of temporin A and modified temporin B in vivo, PLoS One, 4 (2009) e7191.

[6] E. König, O.R. Bininda-Emonds, C. Shaw, The diversity and evolution of anuran skin peptides, Peptides, 63 (2015) 96-117.

[7] J.M. Conlon, J. Kolodziejek, N. Nowotny, Antimicrobial peptides from ranid frogs: taxonomic and phylogenetic markers and a potential source of new therapeutic agents, Biochimica et Biophysica Acta (BBA)-Proteins and Proteomics, 1696 (2004) 1-14.

[8] L. de Azevedo Calderon, E.S. Alexandre de Almeida, P. Ciancaglini, R.G. Stábeli, Antimicrobial peptides from Phyllomedusa frogs: from biomolecular diversity to potential nanotechnologic medical applications, Amino acids, 40 (2011) 29-49.

[9] X. Xi, R. Li, Y. Jiang, Y. Lin, Y. Wu, M. Zhou, J. Xu, L. Wang, T. Chen, C. Shaw, Medusins: A new class of antimicrobial peptides from the skin secretions of phyllomedusine frogs, Biochimie, 95 (2013) 1288-1296. 
[10] M. Zhou, Y. Liu, T. Chen, X. Fang, B. Walker, C. Shaw, Components of the peptidome and transcriptome persist in lin wa pi: the dried skin of the Heilongjiang brown frog (Rana amurensis) as used in traditional Chinese medicine, Peptides, 27 (2006) 2688-2694.

[11] D. Vanhoye, F. Bruston, P. Nicolas, M. Amiche, Antimicrobial peptides from hylid and ranin frogs originated from a 150-million-year-old ancestral precursor with a conserved signal peptide but a hypermutable antimicrobial domain, The FEBS Journal, 270 (2003) 2068-2081.

[12] J.M. Conlon, J. Kolodziejek, N. Nowotny, J. Leprince, H. Vaudry, L. Coquet, T. Jouenne, S. Iwamuro, Cytolytic peptides belonging to the brevinin-1 and brevinin-2 families isolated from the skin of the Japanese brown frog, Rana dybowskii, Toxicon, 50 (2007) 746-756.

[13] L.-L. Jin, Q. Li, S.-S. Song, K. Feng, D.-B. Zhang, Q.-Y. Wang, Y.-H. Chen, Characterization of antimicrobial peptides isolated from the skin of the Chinese frog, Rana dybowskii, Comparative Biochemistry and Physiology Part B: Biochemistry and Molecular Biology, 154 (2009) 174-178. [14] M. NISHIOKA, M. SUMIDA, L.J. BORKIN, Z. WU, Genetic differentiation of 30 populations of 12 brown frog species distributed in the Palearctic region elucidated by the electrophoretic method, Scientific report of the Laboratory for Amphibian Biology, 11 (1992) 109-160.

[15] A. Tossi, L. Sandri, A. Giangaspero, Amphipathic, $\alpha$-helical antimicrobial peptides, Peptide Science, 55 (2000) 4-30.

[16] T. Wieprecht, M. Dathe, M. Beyermann, E. Krause, W.L. Maloy, D.L. MacDonald, M. Bienert, Peptide hydrophobicity controls the activity and selectivity of magainin 2 amide in interaction with membranes, Biochemistry, 36 (1997) 6124-6132.

[17] M.R. Yeaman, N.Y. Yount, Mechanisms of antimicrobial peptide action and resistance, Pharmacological reviews, 55 (2003) 27-55.

[18] K.A. Brogden, Antimicrobial peptides: pore formers or metabolic inhibitors in bacteria ?, Nature reviews. Microbiology, 3 (2005) 238.

[19] S.-H. Park, H.-E. Kim, C.-M. Kim, H.-J. Yun, E.-C. Choi, B.-J. Lee, Role of proline, cysteine and a disulphide bridge in the structure and activity of the anti-microbial peptide gaegurin 5, Biochemical Journal, 368 (2002) 171.

[20] M.C. Geoffrey, E. Robert, The cell: a molecular approach, Boston University, Sunderland, (2000).

\section{Legends to Figures}

Figure 1. The alignment of full length nucleotide sequences (A) and translated open reading frame sequences (B) of the four Amurin-2 variants. Each of the cDNAs contain 310 base pairs encoding 67 amino acids. The identical nucleotidesand amino acid residues are highlighted.

Figure 2. The chromatography of the skin secretion of Rana amurensis. The elution positions/retention times of Amurin-2 and the variants were indicated by arrows.

Figure 3. Physio-chemical properties of synthetic natural peptides and two Lys-substituted analogues. (A) Helical wheel projections of Amurin-2 variants and analogues. The directions of hydrophobic moments of peptides are denoted by the arrows in the middle of the wheels. (B) CD Spectrum of Amurin-2 variants and two analogues in $0.5 / 0.5(\mathrm{v} / \mathrm{v}) \mathrm{NH} 4 \mathrm{AC} / \mathrm{TFE}$. (HMEC-1) with different concentrations $\left(10^{-9}\right.$ to $\left.10^{-4} \mathrm{M}\right)$ of Amurin-2 variants and analogues. 
273

281

82

Table 1. The structure and physio-chemical properties of Amurin-2 variants and analogues. The bold typeface indicates the substituted Lys in the sequences.

\begin{tabular}{llccc}
\hline \multicolumn{1}{c}{ Peptide } & \multicolumn{1}{c}{ Sequence } & Hydrophobicity $<$ H $>$ & Net charge & $\boldsymbol{\alpha}$-helix) \\
\hline Amurin-2 & FLSLALAALPKLFCLIFKKC & 0.955 & 3 & $42 \%$ \\
Amurin-2a & FLPLLLAGLPSFLCLVFKKC & 1.065 & 2 & $69 \%$ \\
Amurin-2b & FLPLLLSALPSFLCLVFKKC & 1.063 & 2 & $59 \%$ \\
Amurin-2c & FLSLALAALPKFLCLVFKKC & 0.925 & 3 & $30 \%$ \\
$\mathrm{~K}^{4}$-Amurin-2 & FLPKLLAGLPSFLCLVFKKC & 0.930 & 3 & $43 \%$ \\
$\mathrm{~K}^{11}$-Amurin-2 & FLPLLLAGLPKFLCLVFKKC & 1.017 & 3 & $61 \%$ \\
\hline
\end{tabular}

Table 2. The minimum inhibitory concentrations (MICs, $\mu \mathrm{M})$ and half haemolytic concentrations $\left(\mathrm{HC}_{50}, \mu \mathrm{M}\right)$ of Amurin-2 variants and analogues.

\begin{tabular}{lccccc}
\hline & \multicolumn{4}{c}{ MIC $(\boldsymbol{\mu M})$} & \multirow{2}{*}{ HC $_{\mathbf{5 0}}(\boldsymbol{\mu} \mathbf{M}){ }^{1}$} \\
\cline { 2 - 5 } & S. aureus & E. coli & C. albicans & MRSA & \\
\hline Amurin-2 & 32 & $>512$ & 32 & 32 & 4.7 \\
Amurin-2a & 128 & $>512$ & $>512$ & $>512$ & 439.0 \\
Amurin-2b & 32 & $>512$ & $>512$ & 512 & 195.9 \\
Amurin-2c & 32 & $>512$ & 32 & 32 & 17.0 \\
$\mathrm{~K}^{4}$-Amurin-2 & 16 & 16 & 8 & 8 & 31.0 \\
$\mathrm{~K}^{11}$-Amurin-2 & 16 & 512 & 16 & 16 & 29.1 \\
\hline
\end{tabular}

${ }^{1}$ The half haemolytic concentrations $\left(\mathrm{HC}_{50}, \mu \mathrm{M}\right)$ were analysed by Graphpad Prism Software.

Table 3. $\mathrm{IC}_{50}(\mu \mathrm{M})$ of Amurin-2 variants and analogues on cancer cell lines and HMEC-1 cell line.

\begin{tabular}{lcccccc}
\hline & \multicolumn{7}{c}{ IC $_{\mathbf{5 0}}(\boldsymbol{\mu} \mathbf{M})$} \\
\cline { 2 - 7 } & H157 & PC-3 & U251MG & MB435S & MCF-7 & HMEC-1 \\
\hline Amurin-2 & 4.5 & 6.4 & 4.6 & 9.5 & 9.1 & 25.2 \\
Amurin-2a & 60.2 & 133.6 & 86.42 & 193.3 & 302.1 & 1545 \\
Amurin-2b & 77.5 & 300.9 & 144.3 & 780.0 & 498.4 & 180.8 \\
Amurin-2c & 10.6 & 7.0 & 4.1 & 10.3 & 14.6 & 35.9 \\
$\mathrm{~K}^{4}$-Amurin-2 & 8.2 & 28.4 & 14.8 & 19.6 & 41.6 & 85.2 \\
$\mathrm{~K}^{11}$-Amurin-2 & 6.9 & 16.0 & 9.2 & 58.1 & 310.6 & 52.1 \\
\hline
\end{tabular}


Amurin-2 Amurin-2a

Amurin-2b Amurin-2c

Amurin-2 Amurin-2a

Amurin-2b

Amurin-2c

Amurin-2

Amurin-2a

Amurin-2b

Amurin-2c

Amurin-2

Amurin-2a

Amurin-2b

Amurin-2c

Amurin-2

Amurin-2a

Amurin-2b

Amurin-2c

Amurin-2

Amurin-2a

Amurin-2b

Amurin-2c

Amurin-2

Amurin-2a

Amurin-2b

Amurin-2c

Amurin-2

Amurin-2a

Amurin-2b

Amurin-2c

241

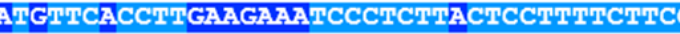

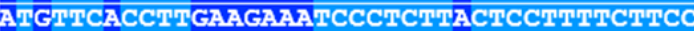

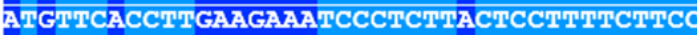

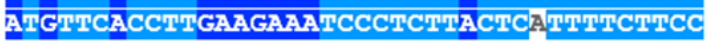

41

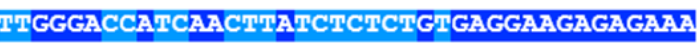
80

NTGGGACCATCAACWHATCTCTCTGTGAGGAGAGAGAA THGGGACCATCAACHUATCTCTCTGTGAGGAGAGAGAAA ITEGGACCATCAAC HUATCTCTCIGIGAGGAGAGAGAAA

IGCCGATGAAGAGAAAGAGAGATGATCICGAAGAAAG 120

IGCCGATGAAGAGAAAGAAGAGATGATCTCGAAGAAAGC TECCGATGAGGAGAAAGAAGAGATATCCCGAAGAAAGG IECCGATGA GAAGAAAGAGAGATATCC CGAAGAAAGE 121

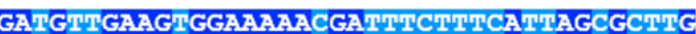
GATGITGACGIGGAAAAACGGTITCIICCATIATIGCTIG

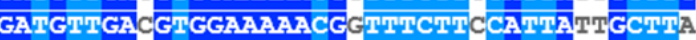

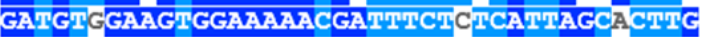

161

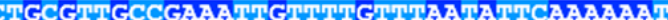

201

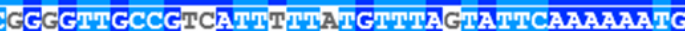

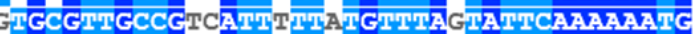

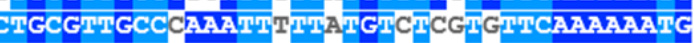

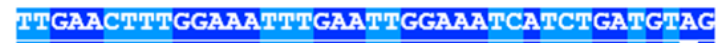

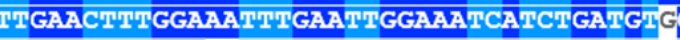

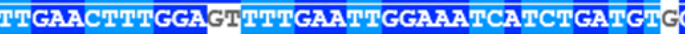

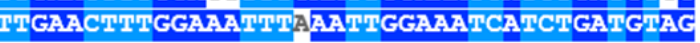

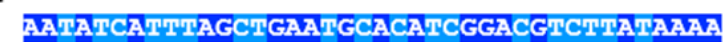

AATATCCA TTTAGITCGAATTGCACATCAGATGTTGTTCC

AATATCATHUAGCTGATIGCACATCAGAT TTCTHATAAAA

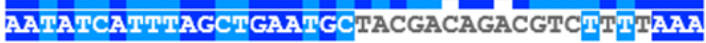
281

MATAAACGIGTGGAGAAAAAAAAAAAAAAP 310

TTATCTAAAAATAAAAACATGTGCATAAAA

AATAAACA TGIGGCATAAAAAAAAAAAAA

AAATTAAAACATETGGCA

(A)

Amurin-2

Amurin-2a

Amurin-2b

Amurin-2c
287

288
MFTLKKSLLLLFFLGTINLSLCEEERNADEEERRDDLEERDVEVEKRELSLALAALPKLFCLIFKKC MFTLKKSLLLLFFLGTINLSLCEEERNADEEERRDDLEERDVDVVKRFIPILIAAGLESFLCLVFKKC MFTLKKSLLLLFFLGTINLSLCEEERNADEEERRDD PGERDVDVEKRFLPLLISALPSFLCLVFKKC MFTLKKSLLI TFFLGTINLSLCEEERNADEEERRDD PEERDVEVEKRFLSLALAALPKFLCLVEKKC

(B) 
Figure 2.

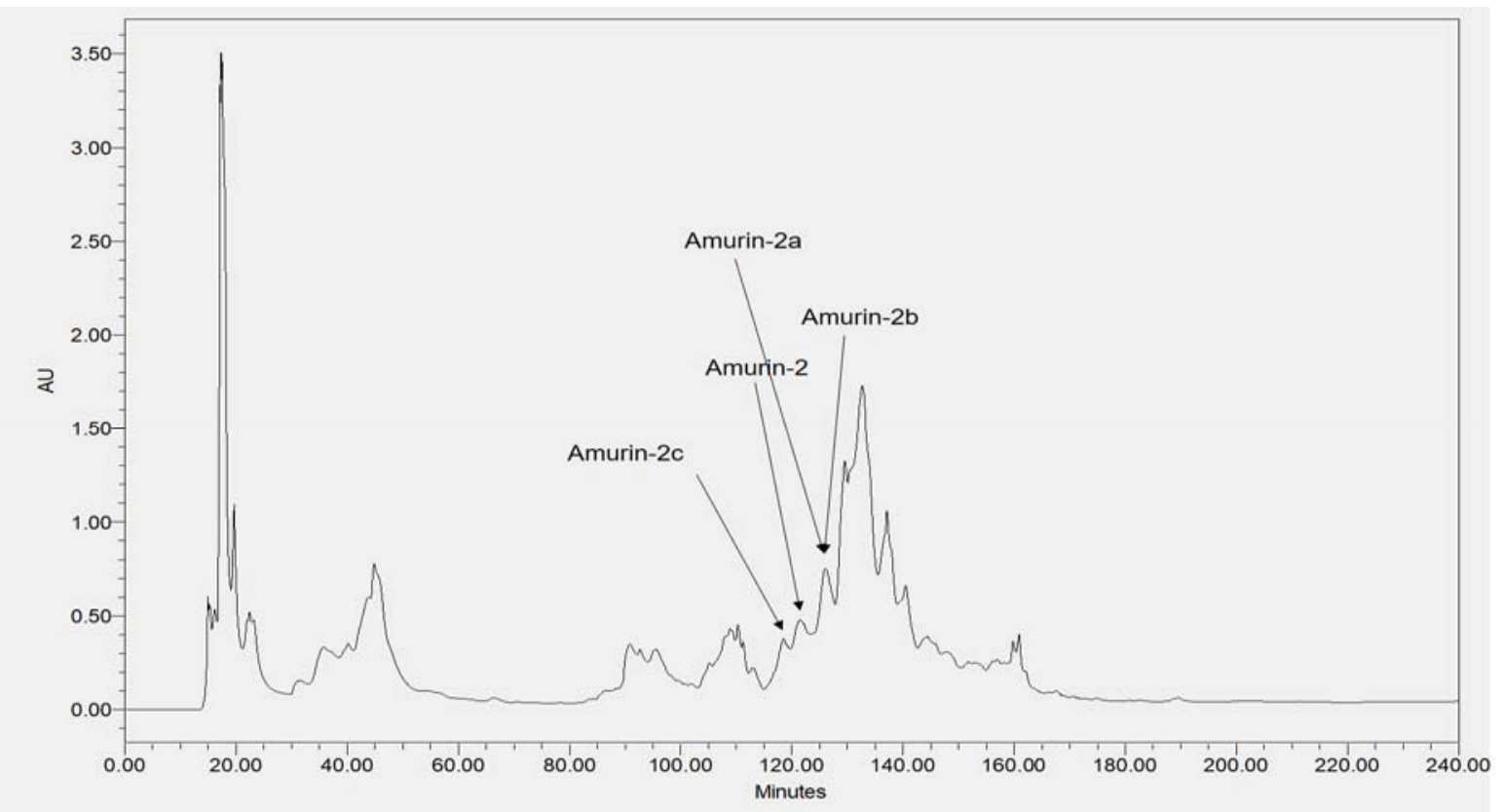

292

293

$294 \quad$ Figure 3.

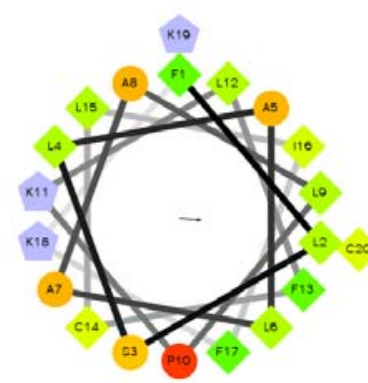

Amurin-2

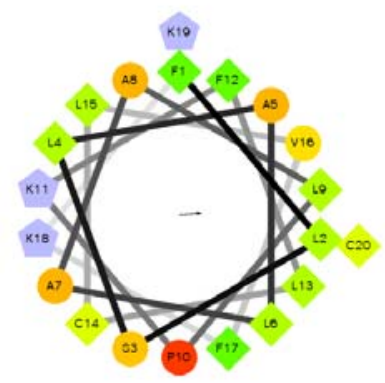

Amurin-2c

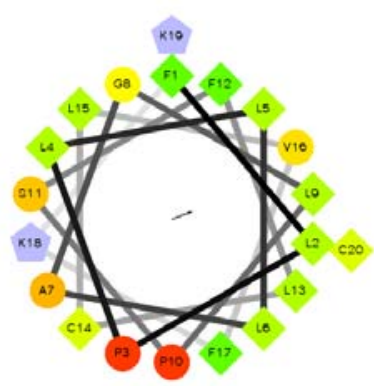

Amurin-2a

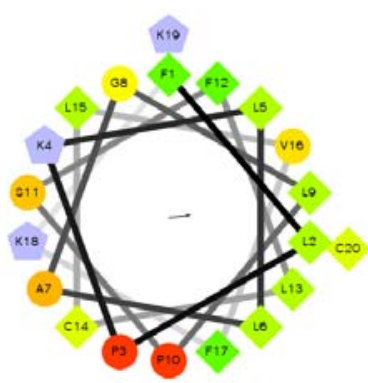

$\mathrm{K}^{4}$-Amurin-2

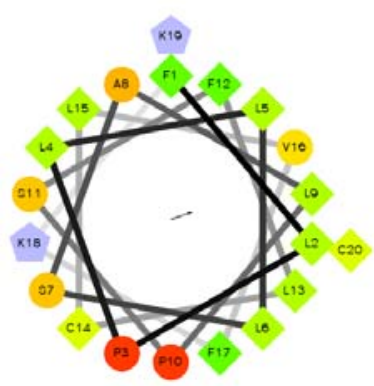

Amurin-2b

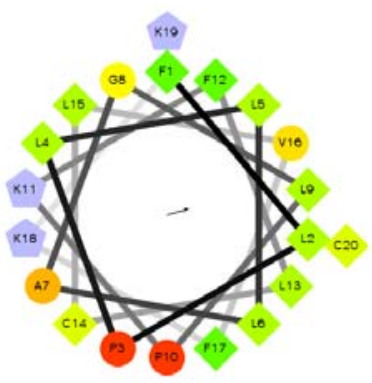

$\mathrm{K}^{11}$-Amurin-2 


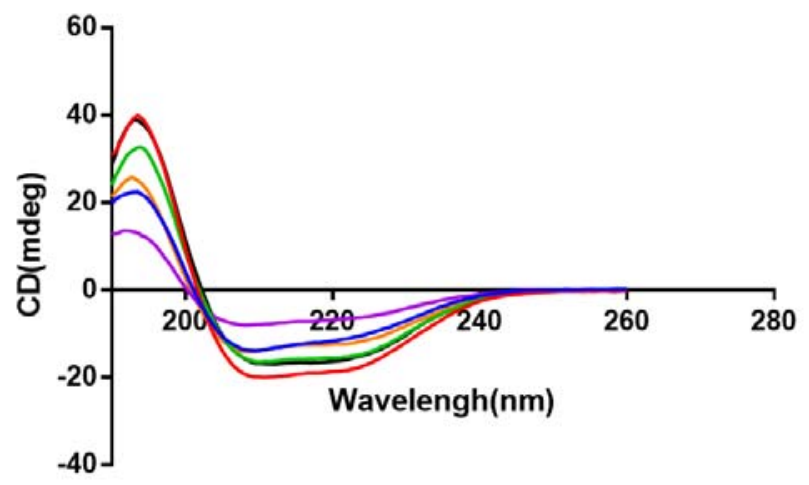

Figure 4.
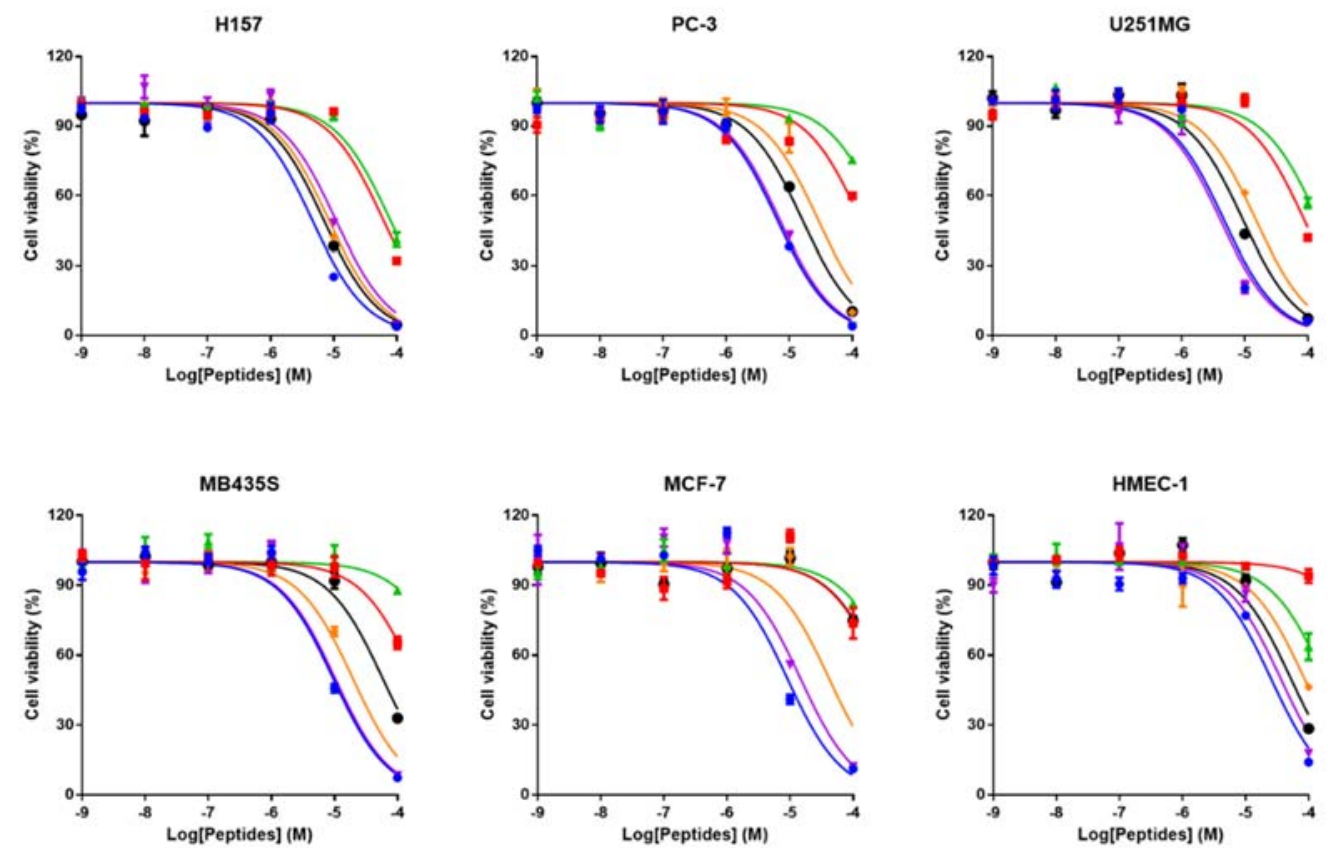